Published online at http://www.nature.com/naturemedicine/.

Reprints and permissions information is available online at http://npg.nature.com/ reprintsandpermissions/.

\section{COMPETING FINANCIAL INTERESTS}

The author declares no competing financial interests.

1. Scudellari, M. Nat. Med. 16, 248 (2010).
2. Peterson, J. Parent cell cultivation could help disease treatment. <https://listserv.utoronto.ca/cgibin/wa?A2=parkinsn;MaCgPw; $19981106080715-0500$ a> (1998).

3. Foley, R.J. Stem cell pioneer warns of roadblocks before cures. GazetteXtra http:// www.gazetteextra.com/stemcells_speech020907.asp (9 February 2007).

4. Stem-cell researchers cautious about timeframe for human cures http://health.dailynewscentral.com/content/view/000813/44 (22 May 2005).

5. Little, M.T. \& Storb, R. Nat. Rev. Cancer 2, 231-238 (2002).

6. Burt, R.K. et al. J. Am. Med. Assoc. 299, 925-936 (2008).

\title{
Improved UK clinical trial capacity through the North West Exemplar Programme
}

\section{To the Editor:}

Laursen ${ }^{1}$ highlights the decline in clinical trials activity within the UK's National Health Service (NHS) over the past ten years and, in particular, the marked reduction in the UK's global market share in commercial clinical trials from 6\% to 2\% between 2000 and 2006 . His article attributes this largely to the introduction of regulation to protect the interests of trial participants and to ensure data integrity. However, many other factors have contributed to this decline, including issues regarding research infrastructure, the provision of skills training for NHS research practitioners and the lack of an effective organizational framework for supporting and coordinating multicenter clinical trials. In addition, changes in the type of studies, including an increase in the number of very large phase 3 trials and improved performance in trials delivery in other countries, have contributed to decline within the UK.

But things are changing rapidly for the better after the introduction of the National Institute for Health Research Clinical Research Network (the NIHR CRN), one of the key components of the strategy for clinical research in England set out in "Best Research for Best Health" published by the UK Department of Health'2 . The NIHR CRN enables trial setup and recruitment to be achieved and supported in a rapid and coordinated manner across the entire country for all areas of disease and health care, with the introduction of resourced and managed systems embedded within the NHS, building on the success of the National Cancer Research Network.

Since the launch of the NIHR CRN, all networks within the northwest of England have worked closely to ensure smooth implementation of the new approach across all the region's 64 NHS trusts, which serve a total population of 6.7 million people - $13 \%$ of England's population. This has enabled swift progress to be made, resulting in selection of this region to undertake the North West Exemplar Programme (http://nwexemplar.nihr.ac.uk). The Exemplar Programme was set up in mid-2009 and brings together all components of the NIHR CRN with industry and NHS partners to demonstrate improved commercial trial performance through every phase of the study life cycle.
The ambition is to achieve or exceed current best European standards for setup and delivery of commercial clinical trials. Specifically, we aim to show that the new NIHR CRN systems improve commercial study performance and reliability, and that the CRN provides added value to NHS trusts and the pharmaceutical and biotechnology industries. During 2010, best practice emerging from the North West Exemplar Programme will be identified for wider implementation across the NHS, industry and the NIHR CRN infrastructure.

Although still in its early stages, the Exemplar Programme is already impressing our industry partners with increased rapidity of trial setup times-for example, median time for approval of Exemplar studies is just 52 days - and, in several instances, the first global or EU patient enrollment. The program will complete its initial phase this month, when more comprehensive data will be available.

Programs such as this demonstrate that there is now considerable reason to feel much more optimistic about the future of clinical trials in the UK.

\section{COMPETING FINANCIAL INTERESTS}

The authors declare no competing financial interests.

John Goodacre 1 , Martin Gibson ${ }^{2}$, Ken Wilson ${ }^{3}$, Zarko Alfirevic ${ }^{3}$, Mike Farrar ${ }^{4}$ \& Janet Darbyshire

${ }^{1}$ NIHR Cumbria \& Lancashire Comprehensive Local Research Network (CLRN), Preston, UK. ${ }^{2}$ NIHR Greater Manchester CLRN, Manchester, UK. ${ }^{3}$ NIHR Cheshire \& Merseyside CLRN, Liverpool, UK. ${ }^{4}$ NHS North West, Manchester, UK. ${ }^{5}$ NIHR Clinical Research Network Coordinating Centre, Leeds, UK.

e-mail: john.goodacre@lthtr.nhs.uk

Published online at http://www.nature.com/naturemedicine/. Reprints and permissions information is available online at http://npg.nature.com/ reprintsandpermissions/.

1. Laursen, L. Nat. Med. 16, 134 (2010).

2. UK Department of Health. Best Research for Best Health: A new national health research strategy. <http://www.dh.gov.uk/prod_consum_dh/groups/dh_digitalassets/@ dh/@en/documents/digitalasset/dh_4127152.pdf> (2006). 